\title{
X-ray Peak Profile Analysis on the Microstructure of Al-5.9\%Mg-0.3\%Sc-0.18\%Zr Alloy Deformed by High Pressure Torsion Straining
}

\author{
Jenő Gubicza ${ }^{1,2}$, Dániel Fátay ${ }^{1}$, Krisztián Nyilas $^{1}$, Elena Bastarash ${ }^{3}$ \\ Sergey Dobatkin ${ }^{3}$ and Tamás Ungár ${ }^{1}$ \\ ${ }^{1}$ Department of General Physics, Eötvös University, Budapest, Hungary \\ ${ }^{2}$ Department of Solid State Physics, Eötvös University, Budapest, Hungary \\ ${ }^{3}$ Moscow State Steel and Alloys Institute (Technological University), Moscow, Russia
}

\begin{abstract}
The microstructure of plastically deformed Al-5.9\% Mg- $0.3 \% \mathrm{Sc}-0.18 \% \mathrm{Zr}$ alloy has been investigated. The severe plastic deformation has been performed by high pressure torsion straining (HPT) up to 15 revolutions at room temperature. The microstructure as a function of the number of revolutions is studied by X-ray diffraction peak profile analysis. It is concluded that the HPT technique results in nanostructure even after 0.5 turn with very high dislocation density. The crystallite size decreases and the dislocation density increases with the number of revolutions, however, after five turns they go into saturation. The edge and the dipole character of the dislocation structure becomes stronger with the increase of the number of revolutions. The value of the crystallite size determined by X-ray peak profile analysis is a bit smaller than the grain size obtained by transmission electron microscopy (TEM).
\end{abstract}

\section{Introduction}

It is well known that alloying of aluminium with scandium with appropriate selection of the composition results in the increase of the recrystallisation temperature above the solidus temperature [1]. As a consequence of this, the heat-treatment of the alloy does not result in grain-growth preserving the high value of the strength. The increase of the recrystallisation temperature is caused by the formation of coherent $\mathrm{Al}_{3} \mathrm{Sc}$ phase in the grain boundaries which hinders the grain boundary motion in the Al alloy [1,2]. During the long term heat-treatments of the $\mathrm{Al}$ alloys, the grain boundary pinning capability of $\mathrm{Al}_{3} \mathrm{Sc}$ particles tends to decrease due to the dissolution and the corsening of these precipitates [1,2]. For increasing the thermal stability of $\mathrm{Al}_{3} \mathrm{Sc}$ particles, $\mathrm{Zr}$ is added to $\mathrm{Al}$ alloys together with $\mathrm{Sc}$ [1]. The $\mathrm{Al}_{3}\left(\mathrm{Sc}_{1-\mathrm{x}} \mathrm{Zr}_{\mathrm{x}}\right)$ phase formed in these alloys preserves all of the positive effects of $\mathrm{Al}_{3} \mathrm{Sc}$ mentioned above $[1,2]$.

The need of producing bulk nanostructured Al alloys leads to the elaboration of the severe plastic deformation (SPD) techniques. In the recent years the SPD methods, e.g. high pressure torsion (HPT), have been widely and successfully used for producing ultrafine grained structure in $\mathrm{Al}$ alloys $[3,4]$. This nanostructure can be retained even at high temperatures with the addition of Sc [5]. The grain size of Al-Sc alloys produced by SPD can be further reduced 
by adding $\mathrm{Mg}[5,6]$. It was found that the $\mathrm{Mg}$ concentration has a strong effect on the superplastic behaviour of these alloys [6].

The analysis of the X-ray diffraction profiles provides information about the microstructure of materials with good statistics. The development in the computer technique permits the fitting of the whole diffraction profiles by theoretical functions calculated on the basis of the model of the microstructure [7-10]. These procedures provide the shape and the size distribution of the crystallites and parameters characterising the defect structure of the crystal lattice. Using the peak profile functions calculated for dislocations, the density and the dipole character of dislocations as well as the dominant dislocation slip system can be determined [11].

Although the effect of the $\mathrm{Sc}, \mathrm{Zr}$ and $\mathrm{Mg}$ additions on the recrystallisation resistance and the strength of the aluminium alloys has been extensively studied [e.g. 1,6], only little information exist on the effect of the extent of SPD on the microstructure of Al-Mg-Sc- $\mathrm{Zr}$ alloys. In this paper the forming of the nanostructure in $\mathrm{Al}-5.9 \% \mathrm{Mg}-0.3 \% \mathrm{Sc}-0.18 \% \mathrm{Zr}$ alloy during HPT is studied by X-ray peak profile analysis. The changes of the crystallite size and the dislocation structure as a function of the number of revolutions are discussed and compared with the results of transmission electron microscopy (TEM).

\section{Experimentals}

An aluminium alloy with the composition of Al-5.9\%Mg- $0.3 \% \mathrm{Sc}-0.18 \% \mathrm{Zr}$ was deformed by HPT. The deformation was performed under $4 \mathrm{GPa}$ pressure on Bridgman anvil at room temperature. The samples of $15 \mathrm{~mm}$ in diameter and $0.6 \mathrm{~mm}$ in thickness were deformed by torsion of $0.5,1,3,5,10$ and 15 rotations.

The microstructure of the high pressure torsion strained specimens was studied by X-ray diffraction peak profile analysis. The diffraction profiles were measured by a Philips X'pert powder diffractometer using $\mathrm{Cu}$ anode and pyrolithic graphite secondary monochromator. The instrumental corrections were made by using the powder pattern of a Si standard (NBS 640a) and the usual Stokes correction procedure. The first 8 reflections were evaluated by the method of Multiple Whole Profile fitting as it is described in Section 3 of this paper.

The microstructure was also investigated by TEM using JEM-100CX microscope. The average grain size was measured on the dark-field micrographs by the linear intercept method.

\section{Evaluation procedure of the X-ray diffraction profiles}

The X-ray diffraction peak profiles were evaluated by the Multiple Whole Profile (MWP) fitting procedure $[9,10]$. In this method after the background subtraction and the instrumental corrections, the Fourier transforms of the measured profiles are fitted by the product of the theoretical functions of size and strain broadening. The calculation of the theoretical funtions is based on a model of the microstructure. In this model it is assumed that the crystallites have spherical shape with log-normal size distribution and the lattice strain is caused by dislocations. The procedure is based on five fitting parameters in the case of cubic crystals: (i) the median $(m)$ and (ii) the variance $(\sigma)$ of the log-normal size distribution function, (iii) the dislocation density $(\rho)$, (iv) the effective outer cut-off radius of dislocations, $R_{e}$, and (v) the 
parameter $q$ describing the average dislocation contrast factors and the edge or screw character of dislocations. The higher the value of $R_{e}$ relative to the average distance between the dislocations $\left(\rho^{-0.5}\right)$, the weaker the dipole character and the screening of the displacement fields of dislocations [12]. The area-weighted mean crystallite size is calculated from $m$ and $\sigma$ as $[7,9]$ :

$$
<x>_{\text {area }}=m \exp \left(2.5 \sigma^{2}\right) .
$$

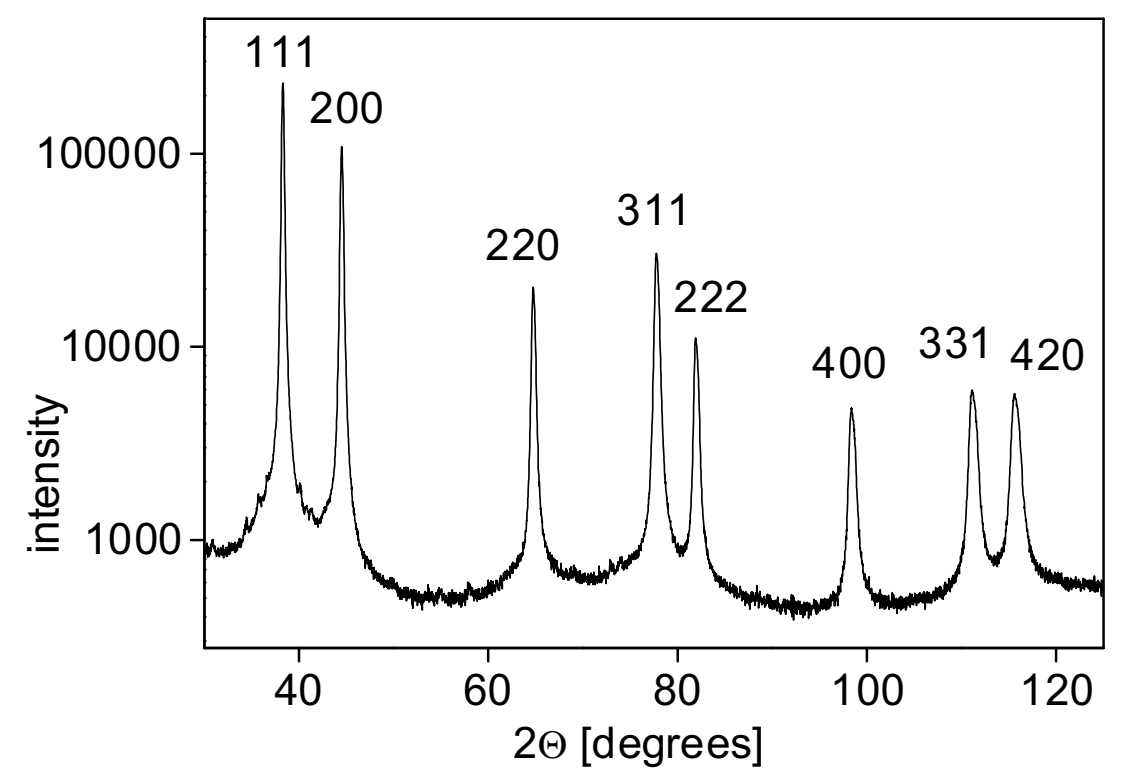

Figure 1. The X-ray diffraction pattern of the alloy deformed by HPT straining for 0.5 revolution.

\section{Results and discussion}

The X-ray diffraction pattern of the alloy deformed by HPT straining for 0.5 revolution is shown in logarithmic intensity scale in Fig. 1. As it can be seen from the figure the main phase is the Al solid solution. The lattice parameter of the aluminium solid solution is $0.40721 \pm 0.00002 \mathrm{~nm}$ which is higher than the value for pure Al, $0.40494 \mathrm{~nm}$. This is probably resulted from the solution of the larger $\mathrm{Mg}$ atoms into the Al lattice. Assuming that the increase of the lattice constant is caused only by the $\mathrm{Mg}$ solute atoms, the $\mathrm{Mg}$ concentration in the solid solution is obtained to be $5.38 \pm 0.03$ at.\% which is less than the nominal value of 5.9 at.\%. In the tail parts of 111 and 200 reflections of the Al solid solution, the peaks of minor phases are observed. For the sake of better visibility, a part of the diffractogram in Fig. 1 is shown in a wider $2 \Theta$ scale in Fig. 2a. The open squares, the open circles and the solid squares in this figure represent the Bragg peaks of $\mathrm{Al}_{3}\left(\mathrm{Sc}_{1-\mathrm{x}} \mathrm{Zr}_{\mathrm{x}}\right), \mathrm{Al}_{3} \mathrm{Mg}_{2}$ and $\mathrm{Al}_{2} \mathrm{Zr}$ phases, respectively. The formation of the $\mathrm{Mg}$-rich $\mathrm{Al}_{3} \mathrm{Mg}_{2}$ phase may be the reason of that the measured $\mathrm{Mg}$ concentration in Al solid solution is lower than the nominal value. The volume fraction of the minor phases estimated from the peak intensities is under $0.3 \%$. Consequently, these phases are not included in the evaluation of the microstructure and their peaks are subtracted from the profiles of $\mathrm{Al}$ solid solution as a background. The lattice parameter of the Al solid solution does not change significantly with the increase of the number of revolutions while the peaks of the minor phases gradually disappear. Fig. $2 b$ shows 
the X-ray diffraction pattern of the specimen deformed for 15 revolutions in logarithmic intensity scale. It can be seen that the peaks of the minor phases almost completely disappeared.

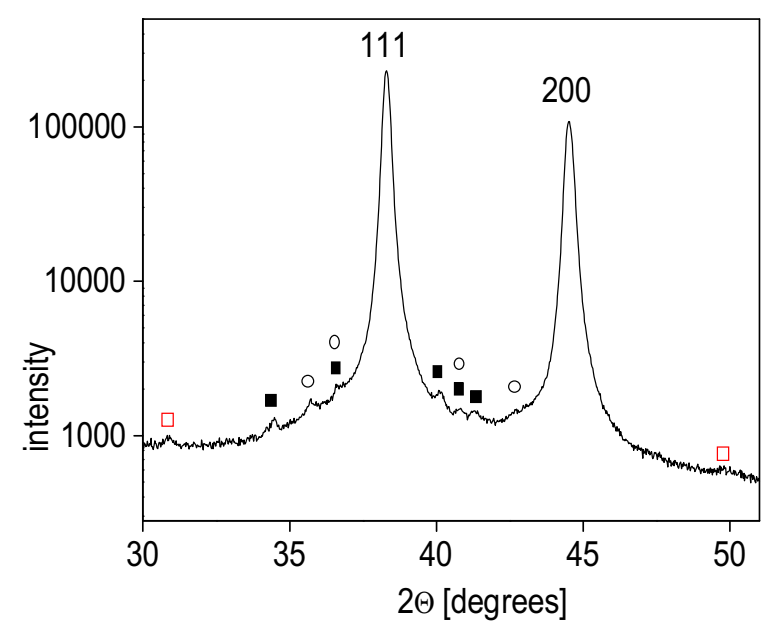

a)

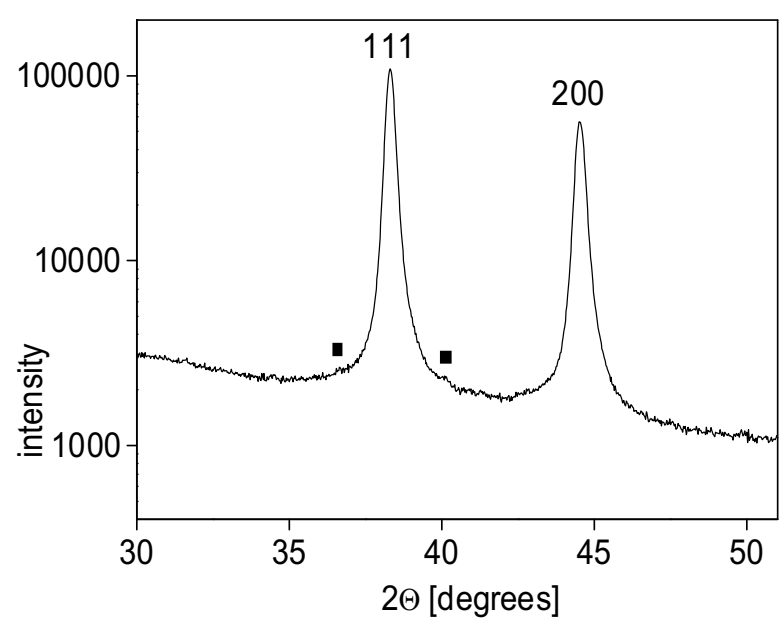

b)

Figure 2. The parts of the diffractograms corresponding to the $2 \Theta$ between 30 and $51^{\circ}$ for (a) 0.5 and (b) 15 revolutions. The open squares, the open circles and the solid squares represent the Bragg peaks corresponding to $\mathrm{Al}_{3}\left(\mathrm{Sc}_{1-\mathrm{x}} \mathrm{Zr}_{\mathrm{x}}\right), \mathrm{Al}_{3} \mathrm{Mg}_{2}$ and $\mathrm{Al}_{2} \mathrm{Zr}$ phases, respectively.

The measured and the fitted Fourier transforms are shown in Fig. 3 for the specimen subjected to 15 revolutions. The difference between the measured and the fitted values is also plotted in the lower part of the figure with the same scaling as in the main part of the figure. The agreement between the measured and the fitted Fourier transforms is good. The quality of the fitting is characterized quantitatively by the weighted least-squares error $\left(R_{w p}\right)$ where the weights are the reciprocal of the observed Fourier transforms. The microstructural parameters obtained from the fitting procedure and the values of $R_{w p}$ are listed in Table 1.

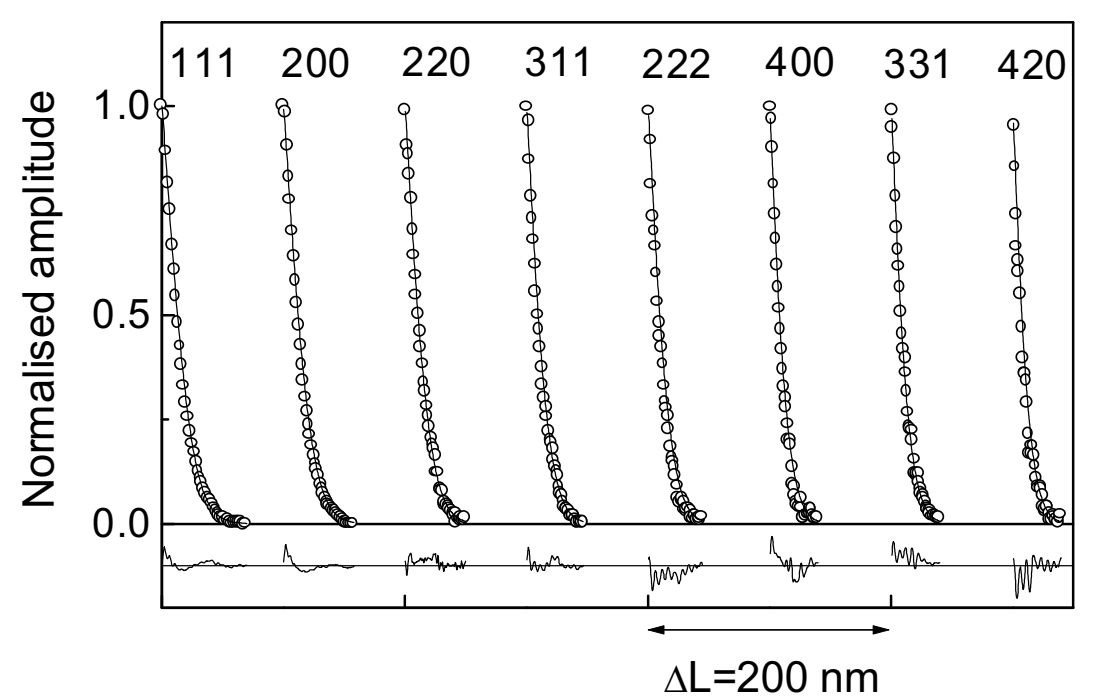

Figure 3. The measured (open circles) and the fitted (solid line) Fourier transforms for the specimen subjected to 15 revolutions. The difference between the measured and the fitted values is also plotted in the lower part of the figure with the same scaling as in the main part of the figure. 
Table 1. The median, $m$, the variance, $\sigma$, of the crystallite size distribution, the area-weighted mean crystallite size, $\langle x\rangle_{\text {area }}$, the dislocation density, $\rho$, the outer cut off radius of dislocations, $R_{e}$, and the weighted least-squares error, $R_{w p}$, for different revolutions of HPT straining.

\begin{tabular}{llllllll}
\hline Revolutions & $\begin{array}{l}m \\
{[\mathrm{~nm}]}\end{array}$ & $\sigma$ & $\begin{array}{c}\left\langle x>_{\text {area }}\right. \\
{[\mathrm{nm}]}\end{array}$ & $q$ & $\begin{array}{l}\rho \\
{\left[10^{14} \mathrm{~m}^{-2}\right]}\end{array}$ & $\begin{array}{l}R_{e} \\
{[\mathrm{~nm}]}\end{array}$ & $\begin{array}{l}R_{w p} \\
{[\%]}\end{array}$ \\
\hline 0.5 & $39 \pm 4$ & $0.36 \pm 0.03$ & $54 \pm 5$ & $0.64 \pm 0.04$ & $16 \pm 2$ & $25 \pm 2$ & 0.6 \\
1 & $37 \pm 3$ & $0.32 \pm 0.02$ & $48 \pm 4$ & $0.59 \pm 0.04$ & $16 \pm 2$ & $26 \pm 3$ & 0.8 \\
3 & $29 \pm 3$ & $0.29 \pm 0.02$ & $36 \pm 4$ & $0.44 \pm 0.03$ & $14 \pm 2$ & $16 \pm 2$ & 0.8 \\
5 & $26 \pm 3$ & $0.37 \pm 0.03$ & $37 \pm 4$ & $0.46 \pm 0.04$ & $24 \pm 2$ & $16 \pm 2$ & 1.0 \\
10 & $30 \pm 3$ & $0.30 \pm 0.02$ & $37 \pm 4$ & $0.42 \pm 0.03$ & $23 \pm 2$ & $13 \pm 2$ & 1.0 \\
15 & $31 \pm 3$ & $0.33 \pm 0.03$ & $40 \pm 4$ & $0.49 \pm 0.04$ & $24 \pm 2$ & $12 \pm 1$ & 1.1 \\
\hline
\end{tabular}

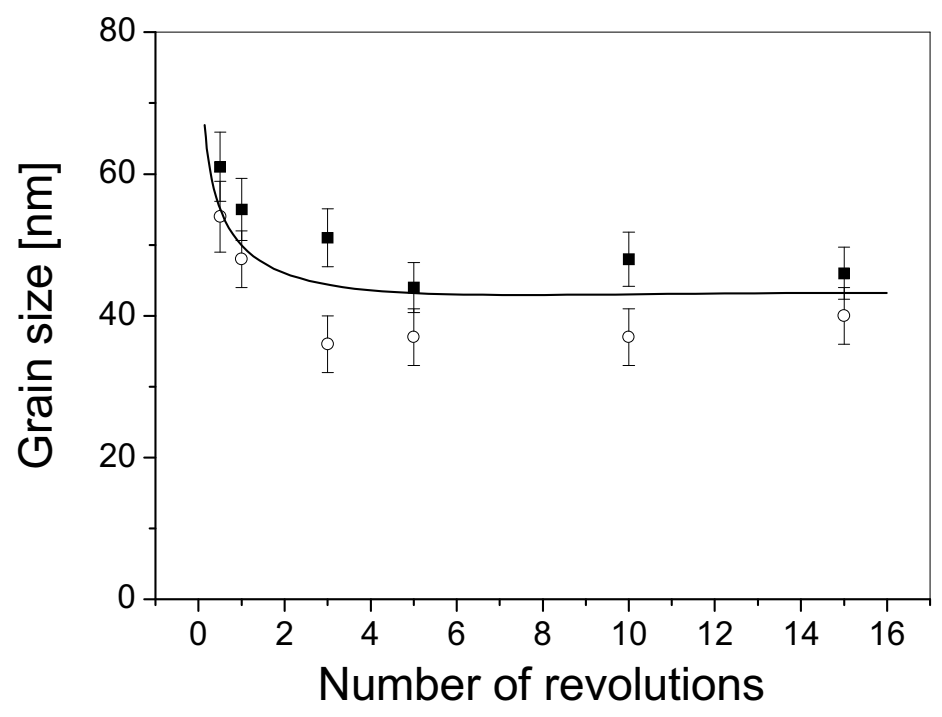

Figure 4. The area-weighted mean crystallite size obtained from X-ray peak profile analysis (open circles) and the grain size determined by TEM (solid squares) as a function of the number of revolutions.

The area-weighted mean crystallite size as a function of the number of revolutions is plotted in Fig. 4. It can be established that the HPT straining technique resulted in nanocrystalline state with crystallite size of $54 \mathrm{~nm}$ even after 0.5 revolution. A slight decrease of the size of the crystallites can be observed up to 5 revolutions but afterwards it goes into saturation. The dislocation density has a high value even after 0.5 revolution, $16 \cdot 10^{14} \mathrm{~m}^{-2}$, and it increases slightly with the increase of the number of turns. The character of dislocations can be obtained from the value of the $q$ parameter. The $q$ parameter values in aluminium for pure screw and edge dislocations of the $<110>\{111\}$ slip system are 1.33 or 0.36 , respectively [11]. The experimental values of the $q$ parameters obtained for the present HPT deformed alloys are listed in Table 1. For all the specimens the value of $q$ is lower than the arithmetic mean of the $q$ parameter values corresponding to the pure edge and screw cases. This indicates that the dislocations have more edge than screw character. A definite tendency of the decrease of the $q$ parameter with the number of rotations can be observed, indicating that the edge character becomes stronger with increasing deformation. The outer cut off radius of dislocations, $R_{\mathrm{e}}$, decreases with the number of revolutions (see Table 1) which means that the dipole character of the dislocations increases, i.e. the screening of the strain field of adjacent dislocations becomes stronger with the deformation. The grain size was determined from 
TEM micrographs for all the specimens and plotted in Fig. 4. It can be established that the values of the crystallite size obtained by X-ray peak profile analysis is somewhat smaller than the grain size determined by TEM.

\section{Conclusions}

The microstructure produced by HPT straining in Al-5.9\%Mg- $0.3 \% \mathrm{Sc}-0.18 \% \mathrm{Zr}$ alloy was studied by X-ray peak profile analysis. It was found that nanostructure was formed even after 0.5 revolution with a crystallite size of $54 \mathrm{~nm}$ and with very high dislocation density of $16 \cdot 10^{14} \mathrm{~m}^{-2}$. The size of the crystallites decreased and the dislocation density increased slightly when the number of turns increased. The edge and dipole character of the dislocation structure became stronger during deformation. After 5 revolutions the microstructure did not change with the increase of turns.

\section{Acknowledgements}

This work was supported by the Hungarian Scientific Research Fund, OTKA, Grant Nos. T031786, T034666, T029701 and by the Magyary Zoltán postdoctoral program of Foundation for Hungarian Higher Education and Research (AMFK). The authors greatly thank Prof. V.V. Zakharov and Dr. T.D. Rostova who kindly presented Al-Mg-Sc-Zr alloy 01570.

\section{References}

1. V. G. Davydov, T. D. Rostova, V. V. Zakharov, Yu. A. Filatov, V. I. Yelagin, Mat. Sci. Eng. A 2000, 280, 30-36.

2. E. A. Marquis, D. N. Seidman, Acta mater. 2001, 49, 1909-1919.

3. V. V. Stolyarov, V. V. Latysh, V. A. Shundalov, D. A. Salimonenko, R. K. Islamgaliev, R. Z. Valiev, Mat. Sci. and Eng. A 1997, 234-236, 339-342.

4. I. V. Alexandrov, R. Z. Valiev, Scripta mater. 2001, 44, 1605-1608.

5. S. V. Dobatkin, V. V. Zakharov, R. Z. Valiev, in Proc. of the First Joint Inter. Conf. "Recrystallization and Grain Growth"(Eds.: G. Gottstein and D. A. Molodov), SpringerVerlag, 2001, 509-514.

6. M. Furukawa, A. Utsunomiya, K. Matsubara, Z. Horita, T. G. Langdon, Acta Mater. 2001, 49, 3829-3838.

7. J. I. Langford, D. Louer, P. Scardi, J. Appl. Cryst. 2000, 33, 964-974.

8. P. Scardi, M. Leoni, Acta Cryst. A 2002, 58, 190-200.

9. T. Ungár, J. Gubicza, G. Ribárik, A. Borbély, J. Appl. Cryst. 2001, 34, 298-310.

10. G. Ribárik, T. Ungár, J. Gubicza, J. Appl. Cryst. 2001, 34, 669-676.

11. T. Ungár, I. Dragomir, Á. Révész, A. Borbély, J. Appl. Cryst. 1999, 32, 992-1002.

12. M. Wilkens, in Fundamental Aspects of Dislocation Theory (Ed.: J. A. Simmons, R. de Wit, R. Bullough ), Nat. Bur. Stand., Washington DC, USA, 1970, Vol. II. Spec. Publ. No. 317, p.1195. 